\title{
Sharing optimal experiences and promoting good community life in a multicultural society
}

\author{
Antonella Delle Fave* and Marta Bassi \\ Dipartimento di Scienze Precliniche LITA Vialba, Università degli Studi di Milano, Milano, Italy
}

(Received 18 December 2007; final version received 11 December 2008)

\begin{abstract}
This study focused on immigrants' quality of daily experience, sources of well-being and future expectations. Theoretical frameworks were research on cross-cultural adaptation and studies on optimal experience. Participants were 159 first-generation immigrants, who moved to Italy from Africa, India, South America, and Eastern Europe. Data were collected through Flow Questionnaire and Life Theme Questionnaire, providing information on optimal experience and associated activities, present challenges and future goals, and on the quality of experience perceived in daily life domains. Results showed that the occurrence of optimal experiences and the features of the associated activities, as well as perceived challenges and goals were primarily connected with the life opportunities offered by the hosting country, along with participants' cultural distance and length of stay. This suggests that information on optimal experiences, perceived quality of daily life and future goals can be useful in designing programs to support immigrants' psychological wellbeing and socio-cultural adjustment.
\end{abstract}

Keywords: cross-cultural research; immigration; optimal experience; socio-cultural adjustment; eudaimonia

\section{Introduction}

An increasing number of researchers are devoting attention to the social and psychological components of a good life. One of the core perspectives in this research focuses on eudaimonia, which implies the harmonization between the individual pursuit of happiness and the realization of community well-being (Ryan \& Deci, 2001). By fulfilling one's daemon or true nature within the community, individuals give meaning to their existence and can contribute to the welfare of other people (Peterson, Park, \& Seligman, 2005). In the present world, individuals and groups often cross their cultural boundaries. This phenomenon calls for the analysis of the cultural representations of happiness and well-being on the one hand (Uchida, Norasakkunkit, \& Kitayama, 2004), and of the relations between individuals and their cultural environment on the other (Delle Fave, 2007). The investigation of these issues can contribute to our understanding of what makes for a good life in a time in human history in which globalization poses a number of challenges. These range from enhanced mobility of people across nations, to ethnic conflicts and to the disruption of traditional civilizations due to the dominance of the Western mono-cultural model (Massimini \& Delle Fave, 2000; Nafstad, Blakar, Carlquist, Phelps, \& Rand-Hendriksen, 2007).

\section{Acculturation, adaptation and well-being}

The growing trend toward multiculturalism that characterizes most Western societies requires more refined instruments to identify the crucial components of acculturation, described as the process of change in collective and individual behaviours that allows a minority group to interact with the norms and habits of a dominant social system (Berry \& Sam, 1997). Acculturation implies two forms of change: sociocultural adjustment (Ward, 2001; Ward \& Kennedy, 1994) and psychological adaptation (Berry, 1997). Socio-cultural adjustment is conceptualized as the degree of immigrants' acquisition of new skills and behaviours; it implies a learning process and the opportunity to interact with host citizens. Several studies highlighted some key predictors of sociocultural adjustment of immigrants, namely the length of residence in the new culture, the relationships with host nationals, the immigrant status (having residence permit versus being 'illegal') and the education level (Ataca \& Berry, 2002; Ward \& Kennedy, 1993; Zlobina, Basabe, Paez, \& Furnham, 2006).

Psychological adaptation refers to emotional wellbeing and satisfaction; however, it is mostly investigated in the perspective of stress and coping, while few studies have focused on the perceived level of wellbeing and goal pursuit among immigrants, and on their

*Corresponding author. Email: antonella.dellefave@unimi.it 
implications for psychological adaptation and sociocultural adjustment. From the perspective of positive psychology, highlighting the positive components of acculturation, such as individual and community resources, strengths and values, can contribute to the pursuit of eudaimonia in multicultural settings. This paper therefore aims at investigating the constructive and purposive dimensions of daily experience and future expectations of immigrants.

Concepts such as happiness and well-being have deep cultural roots (Diener, Oishi, \& Lucas, 2004; Park, Peterson, \& Seligman, 2006; Ryan \& Deci, 2001; Uchida et al., 2004). Cultures shape individuals' wellbeing, not only providing a meaning-making system for daily events and interactions, but also fostering or limiting opportunities for growth and self-expression. Immigration is a particular case of cultural encounters that can have relevant outcomes for the well-being of both the migrating individuals and the host society.

However, besides being influenced by their environment, individuals play an active role in the process of acculturation, in shaping their own developmental pathway, and ultimately in contributing to the changes of the culture they live in (Laland, Odling-Smee, \& Feldman, 2000). In particular, they differentially cultivate activities, values and relationships according to the associated quality of experience. In this process, defined psychological selection (Csikszentmihalyi \& Massimini, 1985), a prominent role is played by optimal experience, a state of engagement, intrinsic motivation and enjoyment (Csikszentmihalyi, 1975; Csikszentmihalyi \& Csikszentmihalyi, 1988), whose positive and rewarding features were confirmed in several cross-cultural studies (Massimini \& Delle Fave, 2000). Optimal experience represents a relevant component of eudaimonic well-being in that it exerts a long-term influence on individual development, by virtue of the preferential cultivation of associated activities through the lifelong process of psychological selection (Delle Fave \& Massimini, 2004a).

In this study, we gathered information among firstgeneration immigrants from Africa, India, South America and Eastern Europe; we investigated the opportunities for optimal experience they retrieved in the new cultural context, the experience they associated with daily domains, their present challenges and future goals. Our first aim was to identify opportunities for well-being in daily life, and their relationship with individuals' projects, psychological adaptation and socio-cultural adjustment. In particular, we expected optimal experience to play a relevant role in these processes. Second, we looked for differences and similarities in perceived well-being and future plans that could be related to the basic predictors of sociocultural adjustment, such as cultural distance from the host country, living conditions and opportunities for interaction with host citizens, and for professional and personal growth. Finally, we aimed at identifying experiential and cultural features that could promote psychological well-being and socio-cultural adjustment of immigrants in the long term.

\section{Method}

\section{Participants}

The sample consisted of 159 first-generation immigrants settled in Italy from Africa $(N=38)$, India $(N=23)$, South America $(N=70)$ and Eastern Europe $(N=28)$. Each immigrant group presented unique cultural features. However, participants were similar within group, in terms of social and economic background. Gender distribution replicated Italian national statistics on foreign residents (ISTAT, 2007). For all participants, the main reason for immigration was to find better job opportunities and to guarantee a higher standard of living to themselves and their families. Most of them planned to settle in Italy in the future, while only a small percentage aimed at going back to their homeland within few years.

African participants comprised 9 women and 29 men aged between 20 and 40 years (mean age $=27.2$ ), 12 of them coming from Somalia, 13 from North Africa (Morocco and Tunisia) and 13 from West Africa (Senegal, Guinea, Ghana, Ivory Coast). As for education, $57.9 \%$ of them had a high school diploma or college degree, $28.9 \%$ completed $8^{\text {th }}$ grade, and $13.2 \%$ elementary school. Most participants $(62.9 \%)$ were single, $34.3 \%$ were married and one was divorced. On average, they had been in Italy for 3 years. No participant had residence permit and regular job; they earned themselves a living through short-term employment opportunities. They had poor housing conditions, and all but two left their family in their homeland. The majority $(92.1 \%)$ was Muslim. Despite these similarities, they came from different cultural backgrounds: immigrants from Somalia had left their country in a period of political and economical instability; Northern Africans came from countries increasingly exposed to Western influence and undergoing fast modernization; Western Africans came from more traditional tribal cultures.

Indian participants included 21 women and 2 men aged between 22 and 53 years (mean age $=41.1$ ). The majority had a university degree, and obtained qualified jobs in Italy as teachers, professionals or managers. Most participants were married (78.3\%), and $21.7 \%$ were single. They had left India 14 years before on average, and had regular residence permit. Most participants were Hindu $(82.6 \%)$ and belonged to socially and economically well-settled families. They showed strong commitment to preserve their original cultural features. 
The South American group consisted of 70 women aged between 20 and 60 years (mean age $=35.8$ ), mainly coming from Peru $(42.7 \%$ ) and, to a lesser extent, from Ecuador, Bolivia, El Salvador and Brazil. As regards education, $66 \%$ of them got a high school degree, $24 \%$ reached $8^{\text {th }}$ grade, and $10 \%$ elementary school. As for family conditions, $36.8 \%$ of these participants were married, but only $16 \%$ lived with their husbands; $36.7 \%$ were single, and $26.5 \%$ divorced. Most participants $(89 \%)$ had children $(2.5$ on average), but only $27.5 \%$ lived with at least one child in Italy. On average, South American immigrants had lived in Italy for 2.7 years. The vast majority had no regular residence permit, but $94.3 \%$ had a job, primarily as caregiver or housemaid to the elderly, while only 4 were unemployed. Most of them $(89.2 \%)$ had been employed in their homeland as shop attendants, teachers and white collar workers. All participants were practicing Christians.

The Eastern European participants were 26 women and 2 men aged between 20 and 56 years (mean age $=37.8)$, mostly coming from Romania (50\%) and, to a lesser extent, from Moldavia, Ukraine, Poland, Bulgaria, Albania and Bosnia. Most of them (89.3\%) obtained a university degree in their homeland. In this group, $39.3 \%$ of the participants were married $(14 \%$ had an Italian spouse), 35.7\% were single and 25\% divorced. Although $39.3 \%$ of them had children, in only three cases were children living in Italy. Participants had lived in Italy for 6 years on average, most of them had a residence permit, and all had a job, $60.7 \%$ as registered nurses and $39.3 \%$ as housemaid or elderly caregiver. Despite the high educational level, only nurses managed to find a matching position in Italy; the others had to accept less qualified jobs than those practiced at home (teacher, chemist, interpreter). Compared with the other groups, these participants came from countries sharing with Italy a closer cultural background; they emigrated during the period of political and economic turmoil following the fall of the Berlin wall.

\section{Measures and procedure}

Participants were administered Flow Questionnaire (FQ) and Life Theme Questionnaire (LT). In FQ they were submitted three quotations describing optimal experience, they were asked to report whether they had such experiences and, if so, to list the associated activities (labelled optimal activities). They were then invited to select from their list the activity providing the most intense and pervasive optimal experiences, and to rate on 0-8 Likert-type scales the level of cognitive, affective and motivational variables perceived in those situations. Through the same scales, participants also rated the average experience associated with three main daily domains: work, being with family, being alone.

The LT investigated the participants' present challenges and future goals through open-ended questions: 'What is the main challenge, problem or dilemma you are facing at present?' and 'What are the most important goals you would like to achieve in the future?' Both FQ and LT provided information on several other aspects of participants' life and experience that will not be discussed here (for more details, see Delle Fave, 2004).

Participants were free to choose whether to fill out the questionnaires on their own or to answer questions in an individual interview format. Indians filled out the questionnaire autonomously. The other participants were interviewed by researchers skilled in the administration of the assessment tools. On average, participants attended one interviewing session lasting about $2 \frac{1}{2}$ hours.

\section{Data analysis}

In line with previous studies (Csikszentmihalyi \& Larson, 1984; Delle Fave \& Massimini, 2004a, 2004b), answers to open-ended questions concerning optimal activities, present challenges and future goals were coded and grouped into broader functional categories corresponding to daily life domains. To the purposes of this study, the answers were grouped as following: productive activities (comprising the categories work, study, volunteering), social relations (family, social relations with friends and other people), leisure (hobbies and sports, use of media), personal care (maintenance, body care and hygiene, eating, resting) and material goods. Answers referring to the psychological domain and personal life were grouped into a separate category, labelled 'thoughts/ introspection' in relation to optimal activities, and 'personal growth' in association with challenges and goals.

The frequency distribution of answer categories was compared across the immigrant groups through $\chi^{2}$ tests. The experience associated with selected optimal activities was evaluated by calculating mean scores for each psychological variable. Non-parametric ANOVAs were then performed to compare the experience across optimal activity categories. We also assessed the quality of experience associated with daily domains (work, being with family, being alone) (1) across immigrant groups, and (2) after dividing participants into two sets: those who reported optimal activities in their lives, and those who did not report any. Non-parametric ANOVAs and Wilcoxon statistics were performed to compare the variable mean values across groups. Due to the large number of tests performed on this data set $(N=36)$, we corrected 
significance levels through the Bonferroni technique, which consists in multiplying obtained $p$ values by the number of tests performed (Bassi \& Delle Fave, 2004).

\section{Results}

\section{Optimal activities among immigrants}

The majority of participants $(68.6 \%)$ reported optimal experiences in their present life. However, as Table 1 shows, differences were detected among groups. All Indians, all but two Eastern Europeans (93\%) and $63 \%$ of the South Americans reported optimal experiences. On the contrary, only $42 \%$ of the Africans did. Moreover, Indians reported the largest average number of optimal activities per participant (4.5 on average), followed by Eastern Europeans (3), Africans (1.3) and South Americans (1.2).

African and Indian participants quoted leisure as the most frequent activity category associated with optimal experience: Africans primarily reported playing soccer; Indians mainly quoted reading and artistic hobbies. For both groups, leisure was followed by productive activities (primarily work). Among Africans, optimal experience was only associated with these two activity categories, while among Indians social relations (both with friends and family members) ranked third in frequency. South Americans and Eastern Europeans mostly associated optimal experience with productive activities (mainly work), followed by social relations (primarily with family members). The third category in frequency was thoughts/introspection for South Americans (with answers such as thinking over past events), and leisure (mainly reading) for Eastern Europeans.

We next compared the distribution of each of the main optimal activity categories across immigrant groups. As participants could list more than one optimal activity, for each category participants in each immigrant group where split into two subgroups: those who had reported that category at least once in their optimal activities list, and those who had not. Therefore, the cell frequencies in each contingency table represented participants, and not activities. We next calculated table and cell $\chi^{2}$ values. Significant differences across groups were detected for productive activities $\left(\chi^{2}(3)=17.1, p<.0007\right)$, social relations $\left(\chi^{2}(3)=11.6, p<.002\right)$ and leisure $\left(\chi^{2}(3)=63.3, p<.0001\right)$. Taking into account the cell $\chi^{2}$ contribution to the total $\chi^{2}$ value, South American participants showed the highest share of optimal experiences in productive activities; Eastern Europeans more frequently reported social relations, and Indians leisure. Africans associated optimal experience with a limited variety of activity categories, primarily the leisure domain. The distribution of selected optimal activities across categories replicated the overall distribution of optimal activities reported in Table 1.

\section{Quality of experience associated with selected optimal activities}

Table 2 illustrates the quality of experience associated with the selected optimal activities. No significant difference was detected across groups in mean values of the variables. Therefore, data were pooled together.

As reported in previous studies (Delle Fave \& Massimini, 2004a, 2005a), optimal activities were associated with a quite positive and rewarding experience. On 0-8 Likert-type scales, all variables scored above the average value (4). However, ANOVA comparisons highlighted significant differences across activity categories for involvement $(F(3)=3.8, p<.02)$, excitement $(F(3)=3.8, p<.02)$, enjoyment $(F(3)=2.9, p<.04)$ and relaxation $(F(3)=5.4, p<.002)$. Results confirmed the main features of optimal experience, namely a stable cognitive core, and variability across activities in the affective and motivational components of experience (Delle Fave \& Massimini, 2005a). Specifically, involvement scored higher during thinking; excitement, enjoyment and relaxation scored higher during leisure.

\section{The quality of experience associated with family, work and solitude}

Each participant was asked to rate the experience associated with three daily domains: being with family, work and being alone. ANOVAs were performed to compare domains across groups. Due to the large number of tests performed $(N=36)$, significance levels were adjusted using a Bonferroni approach, as explained in the method section. All participants associated being with family with a globally positive and rewarding experience. Variables average values ranged between 5 and 7.7 and no significant difference was detected across groups. Therefore, the corresponding results will not be shown here, and we will focus instead on the experience associated with work and solitude (Table 3).

As concerns the experience associated with work, the ANOVA comparison highlighted significant differences for most variables: involvement $(F(3)=8.5$, $p<.004)$, clear feedback $(F(3)=26.3, p<.004)$, intrinsic motivation $(F(3)=17.5, p<.004)$, excitement $(F(3)=15, \quad p<.004)$, enjoyment $(F(3)=28.6, \quad p<$ $.004)$, concentration $(F(3)=9.9, p<.004)$, relaxation $(F(3)=7.6, p<.004)$, clear goals $(F(3)=71, p<.004)$, control $(F(3)=57.1, p<.004)$, challenges $(F(3)=29.1$, $p<.004)$ and skills $(F(3)=60, p<.004)$. Indians, South Americans and Eastern Europeans reported a substantially similar and positive experience, with most 
Table 1. Percentage distribution of optimal activities across cultures.

\begin{tabular}{lcccc}
\hline & Africa & India & South America & Eastern Europe \\
Activity categories & $(P=16, N=21)^{\mathrm{a}}$ & $(P=23, N=104)^{\mathrm{a}}$ & $(P=44, N=53)^{\mathrm{a}}$ & \begin{tabular}{c}
$(P=26, N=79)^{\mathrm{a}}$ \\
\hline Productive activities
\end{tabular} \\
Social relations & 28.6 & 38.5 & 67.9 & 30.4 \\
Leisure & - & 10.6 & 15.1 & 25.4 \\
Thoughts/introspection & - & 49 & 1.9 & 20.3 \\
Personal care & - & 1 & 13.2 & 6.3 \\
\hline
\end{tabular}

Note: Dashes refer to missing values. ${ }^{a} P=$ no. of participants reporting optimal activities, $N=$ no. of optimal activities reported.

Table 2. The quality of experience associated with main selected optimal activities.

\begin{tabular}{|c|c|c|c|c|c|c|c|c|}
\hline & \multicolumn{2}{|c|}{ Productive activities } & \multicolumn{2}{|c|}{ Relations } & \multicolumn{2}{|c|}{ Leisure } & \multicolumn{2}{|c|}{ Thoughts/introspection } \\
\hline & $M$ & $S D$ & $M$ & $S D$ & $M$ & $S D$ & $M$ & $S D$ \\
\hline Involvement & 6.3 & 1.6 & 7.2 & 1.0 & 7.0 & 1.7 & 7.7 & 0.7 \\
\hline Clear feedback & 6.9 & 1.7 & 7.1 & 1.3 & 7.1 & 1.3 & 7.0 & 2.2 \\
\hline Intrinsic motivation & 6.1 & 2.8 & 7.0 & 2.4 & 7.3 & 1.7 & 7.0 & 2.5 \\
\hline Excitement & 6.7 & 1.8 & 7.3 & 0.9 & 7.9 & 0.4 & 6.5 & 2.5 \\
\hline Ease of concentration & 5.6 & 2.7 & 6.6 & 2.6 & 6.8 & 2.4 & 4.9 & 3.4 \\
\hline Enjoyment & 6.8 & 1.7 & 6.2 & 2.6 & 7.6 & 1.0 & 6.0 & 2.4 \\
\hline Concentration & 6.4 & 2.3 & 6.5 & 2.1 & 6.8 & 1.6 & 6.6 & 1.7 \\
\hline Relaxation & 5.8 & 2.3 & 5.9 & 3.4 & 7.7 & 0.9 & 5.1 & 2.7 \\
\hline Clear goals & 7.6 & 1.0 & 7.2 & 1.5 & 7.3 & 1.7 & 6.3 & 3.1 \\
\hline Control & 7.1 & 1.5 & 6.3 & 2.0 & 7.5 & 0.8 & 6.9 & 2.2 \\
\hline Challenges & 6.7 & 1.7 & 6.8 & 1.6 & 6.7 & 2.2 & 6.1 & 2.6 \\
\hline Skills & 7.0 & 1.2 & 6.3 & 1.8 & 6.9 & 2.0 & 6.3 & 2.5 \\
\hline$N$ of participants & \multicolumn{2}{|c|}{60} & \multicolumn{2}{|c|}{13} & \multicolumn{2}{|c|}{26} & \multicolumn{2}{|c|}{10} \\
\hline
\end{tabular}

Table 3. The experience associated with work and solitude by each immigrant group.

\begin{tabular}{|c|c|c|c|c|c|c|c|c|}
\hline \multirow[b]{2}{*}{ Variables } & \multicolumn{2}{|c|}{ Africa } & \multicolumn{2}{|c|}{ India } & \multicolumn{2}{|c|}{ South America } & \multicolumn{2}{|c|}{ Eastern Europe } \\
\hline & $\begin{array}{c}\text { Work } \\
M(S D)\end{array}$ & $\begin{array}{l}\text { Solitude } \\
M(S D)\end{array}$ & $\begin{array}{c}\text { Work } \\
M(S D)\end{array}$ & $\begin{array}{l}\text { Solitude } \\
M(S D)\end{array}$ & $\begin{array}{c}\text { Work } \\
M(S D)\end{array}$ & $\begin{array}{l}\text { Solitude } \\
M(S D)\end{array}$ & $\begin{array}{c}\text { Work } \\
M(S D)\end{array}$ & $\begin{array}{l}\text { Solitude } \\
M(S D)\end{array}$ \\
\hline Involvement & $3.4(2.2)$ & $0.6(1.4)$ & $5.3(2.6)$ & $3.3(3.1)$ & $5.7(2)$ & $3.2(2.3)$ & $5.3(1.6)$ & $3.8(2.1)$ \\
\hline Clear feedback & $3.4(1.9)$ & $0.8(1.6)$ & $6.0(2.7)$ & $3.2(2.8)$ & $7.0(1.7)$ & $5.0(2.8)$ & $6.7(1.4)$ & $5.6(1.9)$ \\
\hline Intrinsic motivation & $2.3(2.5)$ & $0.7(1.7)$ & $3.9(3.4)$ & $2.2(2.1)$ & $6.5(2.8)$ & $3.6(3.1)$ & $5.5(2.5)$ & $3.7(2.4)$ \\
\hline Excitement & $3.0(2.2)$ & 0.7 (1.7) & $5.1(3.1)$ & $4.1(3.2)$ & $6.2(2.2)$ & $4.2(2.8)$ & 6.5 (1.9) & $4.4(2.8)$ \\
\hline Ease of concentration & $3.1(2.3)$ & $0.4(1.2)$ & $5.1(3)$ & $3.5(2.9)$ & $4.6(3.1)$ & $4.8(3)$ & $5.8(2)$ & $6.1(1.5)$ \\
\hline Enjoyment & $2.5(2.2)$ & $0.4(1.1)$ & $5.5(2.8)$ & $3.1(3.1)$ & $6.6(1.8)$ & $3.4(2.7)$ & $5.9(1.8)$ & $4.2(2.3)$ \\
\hline Concentration & $2.5(1.8)$ & $0.4(1.2)$ & $5.0(2.7)$ & $2.8(2.7)$ & $5.3(2.8)$ & $3.9(2.8)$ & $5.4(1.8)$ & $3.6(2.5)$ \\
\hline Relaxation & $3.0(2.5)$ & 1.0 & $4.9(2.8)$ & $5.5(3)$ & $5.3(2.7)$ & $3.9(2.8)$ & $6.0(1.8)$ & 6.3 (1.9) \\
\hline Clear goals & $3.1(2.2)$ & 0.7 (1.4) & $6.9(1.3)$ & $4.3(2.5)$ & $7.5(1.3)$ & $5.8(2.7)$ & $7.5(0.9)$ & 5.9 (1.9) \\
\hline Control & $2.0(2.3)$ & 0.7 (1.7) & 6.7 (1.6) & $5.3(3.3)$ & $7.2(1.8)$ & $6.0(2.4)$ & $6.0(1.8)$ & $6.0(2.3)$ \\
\hline Challenges & $2.1(2.1)$ & $0.5(1.4)$ & $4.5(2.5)$ & $2.2(2.3)$ & $6.4(2.2)$ & $3.6(2.7)$ & $6.4(1.8)$ & $4.0(2.4)$ \\
\hline Skills & $2.7(1.8)$ & $0.7(1.6)$ & $6.2(1.5)$ & $2.8(2.5)$ & $7.3(1.2)$ & $5.2(3)$ & $6.4(1.7)$ & $5.0(2.4)$ \\
\hline$N$ of participants & 30 & 38 & 23 & 23 & 68 & 70 & 28 & 27 \\
\hline
\end{tabular}

values scoring above 5; on the contrary, Africans scored lowest for almost all variables.

On average, solitude was associated with low variable values in all immigrant groups. However, across-group differences were detected for all variables: involvement $(F(3)=15.9, p<.004)$, clear feedback
$(F(3)=30.2, p<.004)$, intrinsic motivation $(F(3)=$ $11.9, p<.004)$, excitement $(F(3)=17.4, p<.004)$, ease of concentration $(F(3)=36.7, p<.004)$, enjoyment $(F(3)=16.8, \quad p<.004)$, concentration $(F(3)=17.2$, $p<.004)$, relaxation $(F(3)=28.4, p<.004)$, clear goals $(F(3)=45.0, p<.004)$, control $(F(3)=44.1$, 
Table 4. The experience associated with work and solitude: comparison between immigrants with and without optimal experiences.

\begin{tabular}{lccccc}
\hline & \multicolumn{2}{c}{ Work } & & \multicolumn{2}{c}{ Solitude } \\
\cline { 2 - 3 } \cline { 5 - 6 } & OE $M(S D)$ & NOE $M(S D)$ & & OE $M(S D)$ & NOE $M(S D)$ \\
\hline Involvement & $5.5(2.2)$ & $4.1(2.2)$ & & $3.1(2.6)$ & $1.9(2.2)$ \\
Clear feedback & $6.3(2.2)$ & $5.6(2.6)$ & & $4.2(2.9)$ & $3.1(3.2)$ \\
Intrinsic motivation & $5.4(3.1)$ & $4.4(3.4)$ & & $3.0(2.9)$ & $2.2(2.8)$ \\
Excitement & $5.7(2.5)$ & $4.7(2.7)$ & & $3.9(3)$ & $2.3(2.7)$ \\
Ease of concentration & $4.9(2.8)$ & $3.7(2.9)$ & & $4.4(3.1)$ & $2.5(2.9)$ \\
Enjoyment & $5.8(2.3)$ & $4.6(2.9)$ & & $3.3(2.8)$ & $1.7(2.3)$ \\
Concentration & $5.2(2.5)$ & $3.3(2.5)$ & & $3.1(2.8)$ & $2.2(2.8)$ \\
Relaxation & $5.2(2.5)$ & $4.0(3)$ & & $4.5(2.9)$ & $2.3(2.8)$ \\
Clear goals & $6.9(1.9)$ & $5.5(2.8)$ & & $5.0(2.9)$ & $2.9(3.1)$ \\
Control & $6.3(2.2)$ & $4.7(3.4)$ & & $5.1(3.1)$ & $3.5(3.2)$ \\
Challenges & $5.7(2.4)$ & $3.8(3.1)$ & & $3.1(2.8)$ & $1.7(2.2)$ \\
Skills & $6.3(1.9)$ & $5.1(2.9)$ & & $4.2(3)$ & $2.2(3)$ \\
$N$ of participants & 107 & 42 & & 108 & 50 \\
\hline
\end{tabular}

Note: $\mathrm{OE}=$ optimal experience reported; $\mathrm{NOE}=$ optimal experience not reported.

$p<.004)$, challenges $(F(3)=15.9, p<.004)$ and skills $(F(3)=25.5, p<.004)$. Again, these differences were mainly due to the African participants.

We further compared the quality of experience associated with work, family and solitude by participants who reported optimal experiences (OE) and by participants who did not report any (NOE). Due to the large number of Wilcoxon tests performed $(N=36), p$ values were again corrected using a Bonferroni approach. Results are shown in Table 4, except for family, because the associated experience was again substantially positive and overlapping for the two groups.

As concerns work and solitude, participants who reported optimal experiences scored higher on all experiential variables. Significant differences were detected in work for involvement $(Z=3.6, p<.008)$, concentration $(Z=4, \quad p<.004)$ and challenges $(Z=3.0, p<.05)$. Furthermore, significant differences were detected in solitude for excitement $(Z=3.1$, $p<.04)$, ease of concentration $(Z=3.6, p<.008)$, enjoyment $(Z=3.2, p<.03)$, relaxation $(Z=4.4$, $p<.004)$, clear goals $(Z=3.8, p<.004)$, control $(Z=3.1, p<.04)$ and skills $(Z=3.5, p<.008)$.

\section{Present challenges and future goals}

Table 5 shows the distribution of present challenges and future goals across groups.

Most participants identified challenges in their present lives. For Africans, productive activities ranked first in frequency, followed by material goods. Finding a stable job and a house were the most frequent answers in the two categories, respectively. Indians most frequently perceived challenges in social relations, primarily in caring for one's children. Productive activities followed (e.g. career advancements), along with personal growth (primarily selfrealization). For both South Americans and Eastern Europeans, the challenges were most frequently related to productive activities and social relations. South Americans mostly referred to finding a stable job and raising children, respectively. Eastern Europeans prominently quoted obtaining better job conditions in the first category, and finding the right partner in the second one. South Americans additionally reported material goods (e.g. solving financial problems), and Eastern Europeans personal growth (self-realization).

We subsequently compared the distribution for each of the most frequent challenge categories across groups. Table and cell $\chi^{2}$ values were calculated on the frequency distribution of participants reporting vs. not reporting that category, as previously described. Significant differences were detected for productive activities $\left(\chi^{2}(3)=19.2, p<.0003\right)$, social relations $\left(\chi^{2} \quad(3)=18.9, \quad p<.0003\right), \quad$ personal growth $\left(\chi^{2} \quad(3)=8.7, \quad p<.04\right)$ and material goods $\left(\chi^{2}\right.$ $(3)=16.6, p<.0008)$. In particular, Africans reported the highest percentage of productive activities and material goods, while Indians the lowest. Conversely, Indians most frequently reported social relations, and Africans least frequently. Finally, Indians and Eastern Europeans reported the highest share of challenges related to personal growth, whereas Africans the lowest.

As shown in Table 5, most participants reported long-term goals, only partially replicating the challenge distribution. For Africans, productive activities ranked first, followed by social relations and personal growth. The most frequent answers were finding a fulfilling job, building a family, having a better life, respectively. Indians, South Americans and Eastern Europeans 
Table 5. Percentage distribution of present challenges and future goals in each immigrant group.

\begin{tabular}{|c|c|c|c|c|c|c|c|c|}
\hline \multirow{2}{*}{ Categories } & \multicolumn{2}{|c|}{ Africa } & \multicolumn{2}{|c|}{ India } & \multicolumn{2}{|c|}{ South America } & \multicolumn{2}{|c|}{ Eastern Europe } \\
\hline & Challenges & Goals & Challenges & Goals & Challenges & Goals & Challenges & Goals \\
\hline Productive activities & 54.5 & 47.5 & 20 & 34.9 & 31.5 & 25.6 & 37.2 & 25.8 \\
\hline Social relations & 9.1 & 23 & 51.4 & 41.9 & 31.5 & 38.5 & 32.6 & 41.9 \\
\hline Leisure & - & - & - & 2.3 & - & 1.7 & - & 4.8 \\
\hline Personal growth & 1.8 & 21.3 & 17.1 & 7 & 9.0 & 14.9 & 18.6 & 14.5 \\
\hline Health & 1.8 & - & 8.6 & 7 & 5.6 & 2.6 & - & 1.6 \\
\hline Material goods & 32.7 & 8.2 & 2.9 & 7 & 19.1 & 16.2 & 9.3 & 11.3 \\
\hline Miscellaneous & - & - & - & - & 3.4 & 0.9 & 2.3 & - \\
\hline$N$ of participants & 38 & 38 & 23 & 22 & 61 & 61 & 28 & 28 \\
\hline$N$ of answers & 55 & 61 & 35 & 43 & 89 & 117 & 43 & 62 \\
\hline
\end{tabular}

Note: Dashes refer to missing values.

prominently quoted social relations, with answers such as having their children settled and offering them good life opportunities. Productive activities ranked second for these three groups. The most frequent answer for Indians and Eastern Europeans was being successful at one's work; for South Americans, it was getting better working conditions. South Americans further reported material goods (buying a house), followed by personal growth (independence, autonomy). The same categories with inverted ranking order were reported also by Eastern Europeans, with answers like reaching internal harmony (personal growth) and buying a house (material goods).

Finally, we compared the frequency distribution of the most frequent goal categories across groups, through the same procedure followed for the other open-ended questions. A significant difference was identified for social relations $\left(\chi^{2}(3)=8.3, p<.05\right)$. Africans prominently contributed to the total $\chi^{2}$ value, reporting this category less frequently than the other groups.

\section{Discussion}

This study investigated the perceived quality of life and opportunities for optimal experiences, life challenges and future goals of immigrants living in Italy. Our first aim was to identify opportunities for well-being in daily life, and their relationship with goals and psychosocial adjustment. Second, we looked for differences and similarities in immigrants' perceived well-being and future plans that could be related to their cultural distance from Italy, to their immigrant status, living conditions and opportunities for professional and personal growth. Finally, we aimed at identifying experiential and cultural features that could promote psychological well-being and socio-cultural adjustment of immigrants in the long term.

All Indian participants, all but two Eastern Europeans and over $60 \%$ of the participants from
South America reported optimal experience in Italy. On the contrary, less than half of the Africans did. Optimal experience was described as a positive and rewarding state by participants in all the four groups. In line with previous studies, it comprised a stable cognitive core characterized by engagement and skill mobilization, while significant differences across activity categories were detected for affective variables (Delle Fave, 2007).

The prominent optimal activities were hobbies and productive activities for Indians and Africans, while Eastern Europeans and South Americans primarily quoted productive activities and social relations. However, group differences were detected in terms of activity variety. In particular, most of the activities reported by Africans and South Americans were included into one category, namely leisure and productive activities, respectively. On the contrary, Indians and Eastern Europeans associated optimal experience with a wider range of activity categories.

The differences between groups as concerns (1) the number of participants reporting optimal experiences, and (2) the variety and number of optimal activities, can be analyzed at both the individual and the sociocultural level. At the individual level, we looked for differences in expectations and goals characterizing participants' migratory project. However, as described above, the main reason why all participants migrated to Italy was to find better life and job opportunities. We cannot exclude the influence of personality traits and other individual variables; however, our data do not provide adequate information about them.

On the contrary, the data gathered in this study offer suggestions concerning the role of socio-cultural components of adaptation in supporting the retrieval of optimal experiences: the length of stay in Italy, the immigrant status, the cultural distance between the homeland and the hosting country, the job opportunities in Italy and the availability of a social and family network providing support. The easier access to optimal experiences for Indians and Eastern 
Europeans can be related to their high education level, their engagement in professionally qualified jobs, the longer period of stay in Italy and their status as immigrants with residence permit. The cohabitation with family members for Indians, and the limited cultural distance from Italy for Eastern Europeans, can represent additional facilitating factors. Most South Americans had no residence permit; in addition, they were culturally more distant than Eastern Europeans in some respects, but they shared with Italians neoLatin linguistic roots and the practice of Catholicism. Moreover, South Americans were engaged in primarily relational jobs, which provided them with opportunities for socialization, exposure to the daily habits of the host culture, but also affective long-term ties with Italian patients and families, as the participants themselves reported. Africans, on the opposite, had to cope with difficulties at all levels: they were culturally distant from Italians as concerns language, religion, and behavioural norms and habits; they had no residence permit; their arrival in Italy dated only 2 years back on average; they had only temporary jobs, requiring unspecialized skills and providing little reward; they left their families in their homeland; and the precariousness of their situation prevented them from building stable relations.

We further explored the experience associated with the main daily domains. All groups reported a globally positive experience with family, with no significant differences. Although many of the participants left their families in their homeland, the improvement of family life standards and the well-being of family members were the main reasons for emigrating to a foreign country. As detected in several cross-cultural studies, family represents the core social unit of most societies. It provides support and protection, fulfilling basic affiliation needs (Oppedal, Roysamb, \& Sam, 2004). The family plays an even more relevant role in the context of immigration: when present, it provides a safe harbour against daily hassles in a new cultural environment; when far away, it makes daily challenges meaningful and worth facing in order to pursue its well-being in the long term.

Immigrants from India, Eastern Europe and South America reported a substantially positive experience during work, while the opposite was true of Africans. This difference can be related to the job structure, as already described. Indians were engaged in highly professional and complex work activities. Most South Americans and Eastern Europeans worked as nurses, housemaids and caregivers. This allowed them to develop competencies and to mobilize resources at different levels: the professional one, the relational one and the cultural one. Africans experienced a high degree of job instability; in addition, their job comprised primarily unqualified manual tasks, low in complexity and intrinsic rewards, and allowing little social interaction.

For all groups, solitude was characterized by disengagement and negative affect. As shown in previous studies (Delle Fave, Bassi, \& Massimini, 2003), people from collectivistic societies consider being alone quite an unnatural event, to be generally avoided. In the present study, however, Africans reported a significantly more negative experience that the other groups. This result can only partially be related to the fact that most of them left their families at home, since many participants from South America and Eastern Europe shared the same condition. At least two other contextual factors could be involved in the interpretation of this finding: the relational aspects of participants' jobs and their standard of living. As for job, most South Americans and Eastern Europeans worked in a relational context. Immigrants from Africa, on the opposite, could find only limited opportunities for interactions in work, due to both the job structure and the frequent job turnover they had to face. As for living standards, they faced job uncertainty, lack of regular immigrant status and poor housing. This condition of marginalization has been widely described as the most disadvantaged circumstance an immigrant can face during the acculturation process (Berry, 1997); it raises doubts about the feasibility of the migratory project and the individual self-perception, thus making solitude a potential source of negative thoughts.

We also compared the experience associated with work, family and solitude between participants who reported optimal experiences and participants who did not. The findings were consistent and complementary to those obtained through the cross-group comparison. In particular, participants who reported optimal experiences described a more positive experience in work activities and solitude. More specifically, in work they perceived higher engagement; in solitude they reported a less unpleasant and disruptive experience, characterized by relaxation and control rather than disengagement and malaise. These findings suggest that, independent of predictors of socio-cultural adjustment, the opportunity for immigrants to retrieve optimal experience in daily activities can contribute to a more positive overall perception of daily life, within the same domain (considering that work is one of the prominent optimal activities) but also across domains. Particularly intriguing is the difference detected in the experience associated with solitude, a condition in which individuals tend to focus on their own inner states and are more vulnerable to the rise of worries or apathy (Csikszentmihalyi \& Larson, 1984; Delle Fave, Bassi, \& Massimini, 2002). Several studies have shown that retrieving optimal experience in daily life contributes to overall psychological well-being, increased performance, stress reduction and psychophysical health (Delle Fave \& Massimini, 1992, 2005b; 
Donner \& Csikszentmihalyi, 1992; Jackson \& Csikszentmihalyi, 1999). On the basis of these empirical findings, we hypothesize that for immigrants finding occasions of engagement, skill development and intrinsic motivation in daily activities can foster a more positive attitude towards both daily challenges and personal resources, thus making the moments of aloneness into opportunities to feel relaxed and at ease. On the opposite, the lack of opportunities for optimal experiences implies disruption of attention, low selfdetermination (Ryan \& Deci, 2000) and disengagement (Delle Fave \& Massimini, 2005a), which become more evident in solitude and in absence of specific tasks. As concerns family, no difference was detected in the associated experience, further stressing the role of family as a support and a source of stability and meaning.

The analysis of present challenges and future goals provided additional insight into participants' sociocultural adjustment and psychological well-being. More specifically, it was possible to evaluate their life perception in the short and in the long term, in terms of basic need satisfaction versus growth in psychological complexity. The joint analysis of challenges and goals highlighted in all groups the pursuit of a long-term life project within the new culture, in which meeting present challenges represented the first step towards aspiring to more complex goals and future selfactualization.

As concerns present challenges, Africans reported the highest percentage of productive activities and material goods, and the lowest share of social relations and personal growth. In contrast, Indians reported the lowest percentage of productive activities, the highest percentage of social relations and the highest percentage of personal growth along with Eastern Europeans. As concerns goals, the major difference was detected in social relations, with Africans reporting the lowest share. More specifically, for Africans, the present challenges were related to satisfying basic needs such as finding a stable job and a house. In the long term, however, these participants aimed at obtaining job satisfaction, building a family and having a better life, with only few references to material goods. South Americans' prominent challenges were related to children and job stability; future goals primarily included children settlement and better work conditions, followed by material goods. Eastern Europeans reported as main challenges the improvement in job conditions, a stable love relationship and self-realization; among goals they primarily quoted well-being of their children, success at work and inner harmony. Indians reported well-being of children as both major challenge and goal, followed by success in work and self-realization.

These results allowed for the identification of a different emphasis on the present life challenges, according to the degree of socio-cultural adjustment reached by the participants. Africans and South Americans, who shared shorter length of residence in Italy, lower educational level and immigrant irregular status, had to deal with basic survival challenges in the short term. On the contrary, Indians and Eastern Europeans were engaged in the achievement of professional advancements, family development and personal growth. However, participants did not show substantial differences in long-term expectations, regardless of their degree of socio-cultural adjustment: immigrants in the four groups declared their long-term pursuit of personal, professional and relational growth. As suggested by several studies, the kind of goals individuals set and pursue sheds light on their level of perceived self-concordance and self-determination in goal orientation (Gong \& Chang, 2007; Sheldon et al., 2004). Participants across groups mostly stressed the intrinsic value of their goals: looking for satisfaction and fulfilment in job; witnessing children's well-being and success in life; pursuing psychological complexity through inner harmony and self-actualization joined participants within the shared perspective of selfselected goals and eudaimonic well-being.

\section{Conclusions}

These results suggest that the investigation of wellbeing can represent a resource for multicultural policies. Immigrants' good life and socio-cultural adjustment could be promoted through the availability of opportunities for optimal experiences in daily activities characterized by high complexity and relational components, thus fostering individual skill development and participation in the host culture, at the same time making expectations of self-directed goals a real possibility and not just a hope. This would promote the effective mobilization of individuals' resources, the expression of their strengths and potential, as well as their active contribution to the host culture's complexity and functioning.

\section{Acknowledgments}

We thank Marcella Cavallo, Andrea Fianco and Corina Pripis for their precious contribution to this work.

\section{References}

Ataca, B., \& Berry, J.W. (2002). Psychological, sociocultural and marital adaptation of Turkish immigrant couples in Canada. International Journal of Psychology, 37, 13-26.

Bassi, M., \& Delle Fave, A. (2004). Adolescence and the changing context of optimal experience in time: Italy 1986-2000. Journal of Happiness Studies, 5, 155-179. 
Berry, J.W. (1997). Immigration, acculturation and adaptation. Applied Psychology: An International Review, 46, 5-34.

Berry, J.W., \& Sam, D. (1997). Acculturation and adaptation. In J. Berry, M. Segall, \& C. Kagitçibasi (Eds.), Handbook of cross-cultural psychology, vol. 3: Social behavior and applications (pp. 291-326). Needam Heights, MA: Allyn \& Bacon.

Csikszentmihalyi, M. (1975). Beyond boredom and anxiety. San Francisco: Jossey-Bass.

Csikszentmihalyi, M., \& Csikszentmihalyi, I. (Eds.) (1988). Optimal experience. Psychological studies of flow in consciousness. Cambridge: Cambridge University Press.

Csikszentmihalyi, M., \& Larson, R. (1984). Being adolescent: Conflict and growth in the teenage years. New York: Basic Books.

Csikszentmihalyi, M., \& Massimini, F. (1985). On the psychological selection of bio-cultural information. New Ideas in Psychology, 3, 115-138.

Delle Fave, A. (2004). A feeling of wellbeing in learning and teaching. In M. Tokoro, \& L. Steels (Eds.), A learning zone of one's own (pp. 97-110). Amsterdam: IOS Press.

Delle Fave, A. (2007). Individual development and community empowerment: Suggestions from studies on optimal experience. In J. Haworth, \& G. Hart (Eds.), Well-being. Individual, community, and social perspectives (pp. 41-56). London: Palgrave Macmillan.

Delle Fave, A., Bassi, M., \& Massimini, F. (2002). Quality of experience and daily social context of Italian adolescents. In A.L. Comunian, \& U.P Gielen (Eds.), It's all about relationships (pp. 159-172). Lengerich: Pabst Science Publishers.

Delle Fave, A., Bassi, M., \& Massimini, F. (2003). Coping with boundaries: The quality of daily experience of Rom nomads in Europe. Psychology and Developing Societies, $15,87-102$.

Delle Fave, A., \& Massimini, F. (1992). Experience sampling method and the measurement of clinical change: A case of anxiety disorder. In M.W. deVries (Ed.), The experience of psychopathology. Investigating mental disorders in their natural settings (pp. 280-289). New York: Cambridge University Press.

Delle Fave, A., \& Massimini, F. (2004a). The cross-cultural investigation of optimal experience. Ricerche di Psicologia, $1,79-101$.

Delle Fave, A., \& Massimini, F. (2004b). Bringing subjectivity into focus: Optimal experiences, life themes, and person-centered rehabilitation. In P.A. Linley, \& S. Joseph (Eds.), Positive psychology in practice (pp. 581-597). New York: Wiley.

Delle Fave, A., \& Massimini, F. (2005a). The investigation of optimal experience and apathy: Developmental and psychosocial implications. European Psychologist, 10, 264-274.

Delle Fave, A., \& Massimini, F. (2005b). The relevance of subjective well-being to social policies: Optimal experience and tailored intervention. In F. Huppert, N. Baylis, \& B. Keverne (Eds.), The science of well-being (pp. 379-402). Oxford: Oxford University Press.

Diener, E., Oishi, S., \& Lucas, R. (2004). Personality, culture, and subjective well-being: Emotional and cognitive evaluations of life. Annual Review of Psychology, 54, 403-425.
Donner, E., \& Csikszentmihalyi, M. (1992). Transforming stress to flow. Executive Excellence, 9, 16-18.

Gong, Y., \& Chang, S. (2007). The relationships of crosscultural adjustment with dispositional learning orientation and goal setting. Journal of Cross-cultural Psychology, 38, $19-25$.

ISTAT. (2007). Bilancio demografico e popolazione residente straniera al 31 dicembre 2006 per sesso e cittadinanza [Demographic records and foreign resident population up to 31 December 2006 by gender and citizenship]. Retrieved November 13, 2007, from http://demo.istat.it

Jackson, S.A., \& Csikszentmihalyi, M. (1999). Flow in sports: The keys to optimal experiences and performances. Champaign, IL: Human Kinetics.

Laland, K., Odling-Smee, J., \& Feldman, M. (2000). Niche construction, biological evolution, and cultural change. Behavioral \& Brain Sciences, 23, 131-146.

Massimini, F., \& Delle Fave, A. (2000). Individual development in a bio-cultural perspective. American Psychologist, $55,24-33$.

Nafstad, H.E., Blakar, R.M., Carlquist, E., Phelps, J.M., \& Rand-Hendriksen, K. (2007). Ideology and power: The influence of current neo-liberalism in society. Journal of Community and Applied Social Psychology, 17, 313-327.

Oppedal, B., Roysamb, E., \& Sam, D.L. (2004). The effect of acculturation and social support on change in mental health among young immigrants. International Journal of Behavioral Development, 28, 481-494.

Park, N., Peterson, C., \& Seligman, M.E.P. (2006). Character strengths in fifty-four nations and the fifty US states. Journal of Positive Psychology, 1, 118-129.

Peterson, C., Park, N., \& Seligman, M.E.P. (2005). Orientations to happiness and life satisfaction: The full life versus the empty life. Journal of Happiness Studies, 6, 25-41.

Ryan, R., \& Deci, E. (2000). Self-determination theory and the facilitation of intrinsic motivation, social development, and well-being. American Psychologist, 55, 68-78.

Ryan, R., \& Deci, E. (2001). On happiness and human potentials: A review of research on hedonic and eudaimonic well-being. Annual Review of Psychology, 52, 141-166.

Sheldon, K.M., Elliot, A.J., Ryan, R.M., Chirkov, V., Kim, Y., Wu, C., et al. (2004). Self-concordance and subjective well-being in four cultures. Journal of Crosscultural Psychology, 35, 209-223.

Uchida, Y., Norasakkunkit, V., \& Kitayama, S. (2004). Cultural constructions of happiness: theory and empirical evidence. Journal of Happiness Studies, 5, 223-239.

Ward, C. (2001). The A, B, Cs of acculturation. In D. Matsumoto (Ed.), The handbook of culture and psychology (pp. 411-445). Oxford: Oxford University Press.

Ward, C., \& Kennedy, A. (1993). Where's the 'culture' in cross-cultural transitions? Comparative studies on sojourner adjustment. Journal of Cross-cultural Psychology, 24, 221-249.

Ward, C., \& Kennedy, A. (1994). Acculturation strategies, psychological adjustment, and socio-cultural competence during cross-cultural transitions. International Journal of Intercultural Relations, 18, 329-343.

Zlobina, A., Basabe, N., Paez, D., \& Furnham, A. (2006). Sociocultural adjustment of immigrants: Universal and group predictors. International Journal of Intercultural Relations, 30, 195-211. 